\title{
Effective International Knowledge Exchange to Rehabilitate Rivers in Urban Delta's with RDM approach
}

\author{
Floris Boogaard ${ }^{1,2^{*}}$, Eric de Boer ${ }^{1}$, Rick Heikoop ${ }^{3,4}$, and Marius Palsma ${ }^{5}$ \\ ${ }^{1}$ Hanze University of Applied Sciences Groningen, Zernikeplein 11, Groningen, The Netherlands \\ 2 TAUW BV, Zekeringstraat 43, PO 20748, Amsterdam, The Netherlands \\ ${ }^{3}$ Rotterdam University of Applied Sciences Rotterdam, G.J. de Jonghweg 4-6, Rotterdam, The \\ Netherlands \\ ${ }^{4}$ RDM Centre of Expertise Rotterdam, Heijplaatstraat 23, Rotterdam, The Netherlands \\ ${ }^{5}$ Waterwegen consultancy, Gasthuiskamp 23,7203 BH Zutphen, The Netherlands
}

\begin{abstract}
In coastal and low-lying vulnerable delta cities, such as the Rotterdam Metropolitan region and Metropolitan Manila, there has been an increase in vulnerability of urban flooding and water quality problems. New approaches address the current and future effects of climate change and increase urban quality, reduce vulnerability and increase water quality. New arrangements for international cooperation are set up in order to address these problems in the project 'IWASTO' ('to correct and to prevent') where several organisations from the Philippines and The Netherlands join forces to rehabilitate rivers and introduce new innovations for water quality monitoring and waste collection using the 'Research Design and Manufacaturing (RDM)' approach. One of the concrete results from this RDM approach in 2016 is the development and implementation of the 'Longganisa', a waste collection tool that was designed by a DutchPhilippine team. In addition, the waterquality was measured and mapped with innovating methods using apps in order to locate and prioritize highly polluted areas. In the near future measures will be implemented to rehabilitate the rivers in Manila and a knowledge exchange forum will be set up to share the best management practices on international scale in countries as Indonesia, India and China.
\end{abstract}

\section{Introduction}

Urbanisation usually leads to degradation of the urban dense area by e.g. soil sealing, air, water and soil pollution with the result that humans are exposed to floods, contaminants and loss of biodiversity. Some of the biggest challenges are to bring down city temperatures, increase biodiversity, fight water shortages and protect properties from damage by flooding within small budgets and timeframes [1]. In 2016 the entire Cebu province was under a state of calamity due to drought [2] and Philippine temperatures reached dangerous levels [3].

\footnotetext{
*Corresponding author: floris@noorderruimte.nl
} 


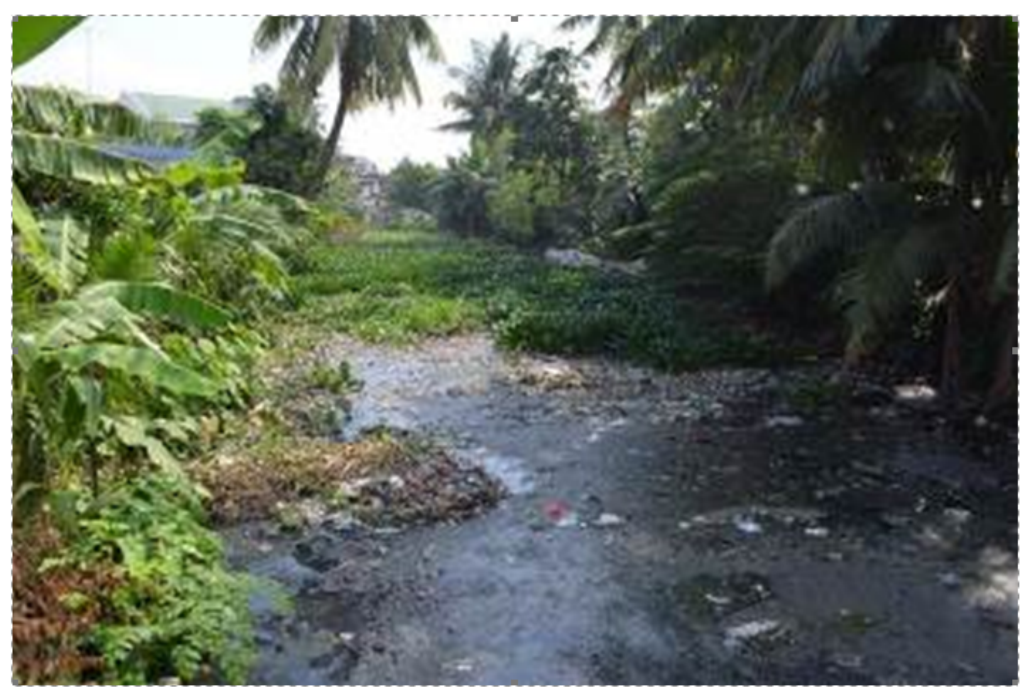

Fig. 1. Degradation of waterways in Manila

Given the worldwide increase in urbanization, and the impact of urban storm water and wastewater on both humans and aquatic ecosystems, the management of our water systems is a critically important challenge [4]. Mega cities, such as metropolitan Manila typically face rapid expansion and uncontrolled urban sprawl, resulting in the lack of infrastructure and wastewater treatment facilities. Urbanization also increases the variety and quantities of pollutants found in downstream receiving waters [5]. Metropolitan Manila is an example of a metropolis where rapid urban growth resulted in a river system that is biologically dead [6], as depicted in Fig. 1.

The quality of the river system in Metro Manila seems to be a status quo, which can not be changed. However, if we look at other similar cases in Europe such as the Amsterdam canals with UNESCO world heritage status [7], we see that these canals were not suitable for swimming decades ago [8,9], but in 20162966 swimmers participated in the Amsterdam City Swim in the Amsterdam canals.

The European experiences with achieving this improvement in water quality is applied to Manila, using the so called 'RDM-approach'. In this article the implementation of this international study is described and recommendations for the rehabilitaion process of the river system in Metro Manila are given as 'lessons learnt' for upscaling this method to countries as Indonesia, India and China.

\section{Method}

In the international knowledge exchange on rehabilitation of rivers, several research methods are applied such as: literature review, participatory waterquality monitoring, surveys and engagement of several stakeholders in interdiciplinair workshops. All information has been mapped on interactive international tools as www.climatescan.nl (Fig. 2) showing videos and photos of problems and solutions in Manila and other locations in the world. Visualisation of the fieldtrips, serious gaming, apps, articles and interactive (field)presentations in several workshops are also used as international knowledge exchange and engagement of stakeholders. 
The main goal of the involved partners is to rehabilitate rivers and to become a showcase for river rehabilitation for other delta cities around the world. A network is being set up with other projects as the India Ganges riverfront project (Kanpur) and 'Transit oriented development \& smart micro city' in China [10] and partners in Indonesia in order to exchange knowledge on solutions to improve the waterquality in a cost effective integrated way. The RDM approach is applied for establishing this international multidisciplinary group of experts and end users. The RDM method is based on the Community of Practice theory described by Wenger in 2001 [11]. Wenger identified three required components to organise interaction on a shared topic and to facilitate incremental change:

1. There needs to be a domain

2. There needs to be a community.

3. The members are practitioners.

In addition to these components triple helix networks elements are added to the model. The triple helix institutional actors are typically University-Industry-Government (U-I-G), which can create synergy and enhance innovative capabilities of countries [12] and even more so if these networks could evolve into a quadruple helix which includes Civil organisations (U-I-G-C) [13]. The Port of Rotterdam in which the RDM campus is located is a strong supporter of new innovate networks to enhance sustainability in Rotterdam's City Ports Area [14]. The research 'The impact of Triple Helix agents on entrepreneurial innovations'performance' [15] concludes that the positive effects of government subsidies is only evidenced when enterprises collaborate with universities.

The IWASTO project is set up to be able to facilitate change and to organise interaction between partners on the shared interest of river rehabilitation, the project started by the implementation of the RDM approach.

\subsection{IWASTO}

IWASTO, which means to correct and to prevent in Tagaloc, is a collaborative project of the Rotary Club of Makati Pasong Tamo, Department of Interior and Local Government, several Dutch (applied) universities and companies. The goal of IWASTO is to rehabilitate and sustain the integrity of the decaying and heavily polluted Pateros River for the sake of ecological balance and disease and flood prevention in the barangay areas that are most affected during natural and man-made calamities. The Pateros River traverses 11 barangays and affects the lives of around two million people: the local residents of the barangays of Pateros, Taguig, Pasig and Makati, and their respective business districts that line the banks of the Pateros River (Fig. 2). 


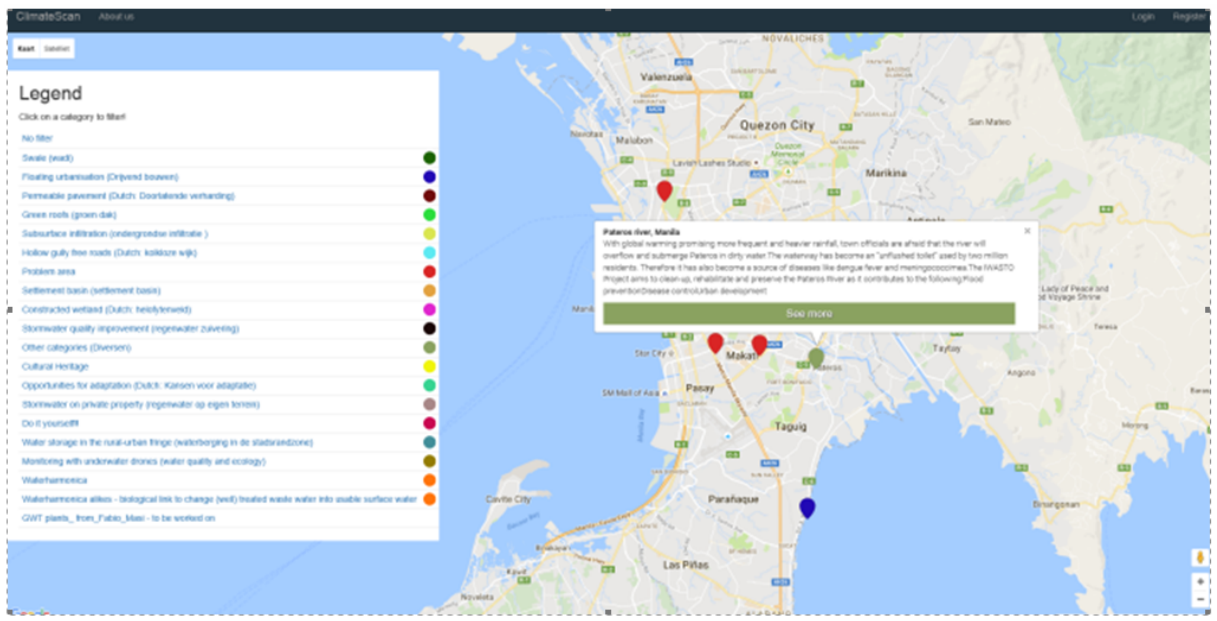

Fig. 2. Pateros river case as shown on knowledge exchange platform www.climatescan.nl [16].

The first IWASTO actions that are planned [7]:

- Stakeholder analysis

- Assessment of the local situation

- Identifications of ambitions

- Cleaning up solid waste that floats in the river

- Initiate behavioural changes to prevent river pollution

- Improving the drainage system

- $\quad$ Education: public awareness (waste management, circular economy)

- Implementing innovating nature based solutions

- Monitoring of water quality by means of low-cost sensors in the river

- $\quad$ Evaluation \& governance

The multiannual programme "IWASTO" aims to bring together Philippine and Dutch expertise in the fields of spatial planning, urbanization, mobility, spatial economics, civil engineering, water management, social science and other fields, in order to develop a sustainable vision for Manila and other cities. A 'meet in the middle strategy' is used which is a unique combination of a 'bottom up' and 'top down approach'. Following the mapping stage locations are prioritized and detailed solutions are designed to face the multiple challenges, such as innovating wastewater treatment and sustainable urban drainage systems on street level.

\subsection{The RDM-approach}

The RDM approach is widely accepted in The Netherlands and mostly located in the presence of (applied) universities as 'BuildingG' and 'EnTranCe' in Groningen, 'Watercampus' in Leeuwarden, 'YesDelft' in Delft and 'RDM campus' in Rotterdam. Within the Rotterdam RDM Centre of Expertise (RDM CoE) educational institutes, research centres and companies cooperate to improve technical education, create new knowledge and accelerate innovations that are necessary for the port and city of Rotterdam. $\mathrm{RDM} \mathrm{CoE}$ is a Centre of Expertise of Rotterdam University of Applied Sciences recognized by the Ministry of Education, Culture and Science that has been set up on the campus of RDM Rotterdam, as part of a public-private partnership with the Port of Rotterdam Authority, the City of Rotterdam and other organizations. RDM CoE is the 
innovation engine for port and city. RDM Centre of Expertise focuses on wicked challenges that are difficult to address with multi stakeholder involvement. This cooperation takes place in innovative configurations such as Communities of Practice $(\mathrm{CoP})$, where private firms and government agencies work together on applied research in collaboration with knowledge institutes [17]. Communities of Practise have been set-up in the fields of Maritime \& Offshore, Logistics \& Mobility, Energy \& Process Technology, New Manufacturing Industry and Circular \& Floating Construction.

According to Wenger [11], Communities of Practice can be defined, in part, as a process of social learning that occurs when people who have a common interest in a subject or area collaborate over an extended period, sharing ideas and strategies, determine solutions, and build innovations. Wenger gives a simple definition: "Communities of practice are groups of people who share a concern or a passion for something they do and learn how to do it better as they interact regularly".

A CoP is distinguished by three required components:

1. There needs to be a domain

2. There needs to be a community.

3. The members are practitioners.

1. There needs to be a domain. A CoP needs a shared domain of interest. Membership implied commitment to the domain and willingness to collaborate with the partners in this specific domain.

2. There needs to be a community. A necessary component is that members of a specific domain interact in shared activities, help each other, and share information with each other. They build relationships that enable them to learn from each other. There needs to be people who interact and learn together in order for a CoP to be formed.

The third requirement is that the members are practitioners. They develop a shared repertoire of resources which can include stories, helpful tools, experiences, stories, ways of handling typical problems, etc. This kind of interaction needs to be developed over time. Informal conversations held by people with the same passion and interests and a variety of professions and disciplines (including graduate students) help people share and develop a set of cases and stories that can become a shared repertoire for their practice, whether they realize it or not. Communities develop their practice through a variety of methods, including: problem solving, requests for information, seeking the experiences of others, reusing assets, coordination and synergy, discussing developments, visiting other members, mapping knowledge and identifying gaps [11].

The RDM-approach entails the acceleration of innovation in the Rotterdam metropolitan area which includes the largest port of Europe, by using a Communities of Practices method and in addition to that a structured approach towards problem solving within the triple helix collaboration in a living lab context. The approach focuses on applied research and applied solutions based on actual problems in the Rotterdam area. Knowledge is created by the involvement of both the private and public sector and knowledge institutes (U-I-G). The $\mathrm{RDM}$ campus and RDM Centre of expertise provide for the tangible facilities and the creation of intangible favourable conditions where partners can meet and come together, namely the Innovation Dock. The Innovation Dock is a $23.000 \mathrm{~m}^{2}$ former shipyard which has been transformed into a state of the art testing facility (height 20 meters), see Fig 3. 


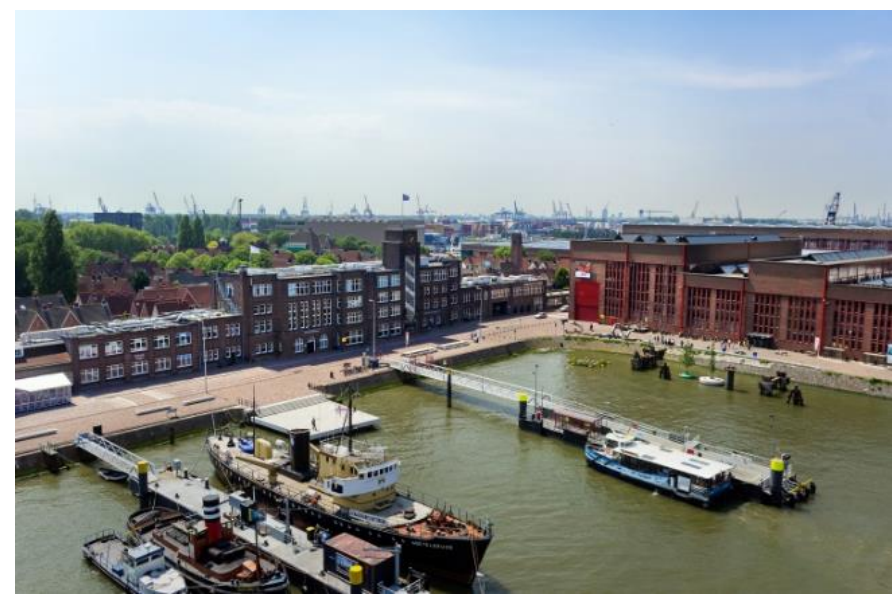

Fig. 3. RDM campus, a former shipyard transformed into a knowledge centre where public, private and knowledge institutes work together on innovations [17].

The presence of high-tech prototypes and testing facilities and the collaboration of many innovative companies and start-ups at the Innovation dock make it a breeding ground for innovations. The continuous presence of students of different disciplines enhance the innovative atmosphere. Companies that wish to locate in Innovation Dock sign a contract which includes the condition that the companies involve students in their operations. In this way entrepreneurial thinking and real-life problem solving structurally slips into the head and mind of a new generation of students.

This triple helix approach (see Fig. 4) is materialised in the formulation of specific assignments from the private and public sector which are brought into the curricula and practice oriented research projects of the different courses (86 full time courses) at Rotterdam University. This approach helps to bring the 'real world' into the undergraduate education and reduces the distance to the labour market of young professionals.

The Living Lab Approach focuses on co-producing knowledge while recognising that the immense urban and societal challenges we are facing demand concerted collaborative efforts across sectors as well as between disciplines [18]. Co-production involves stakeholders understanding each other's contexts; in order to work together to frame research that delivers solutions that are more effective. While the range of initiatives that call themselves living labs is diverse, three core characteristics distinguish them from other approaches such as internships or practicums [19]: they comprise a geographically or institutionally bounded space, they conduct intentional experiments that make social and/or material alterations, and they incorporate an explicit element of iterative learning. 


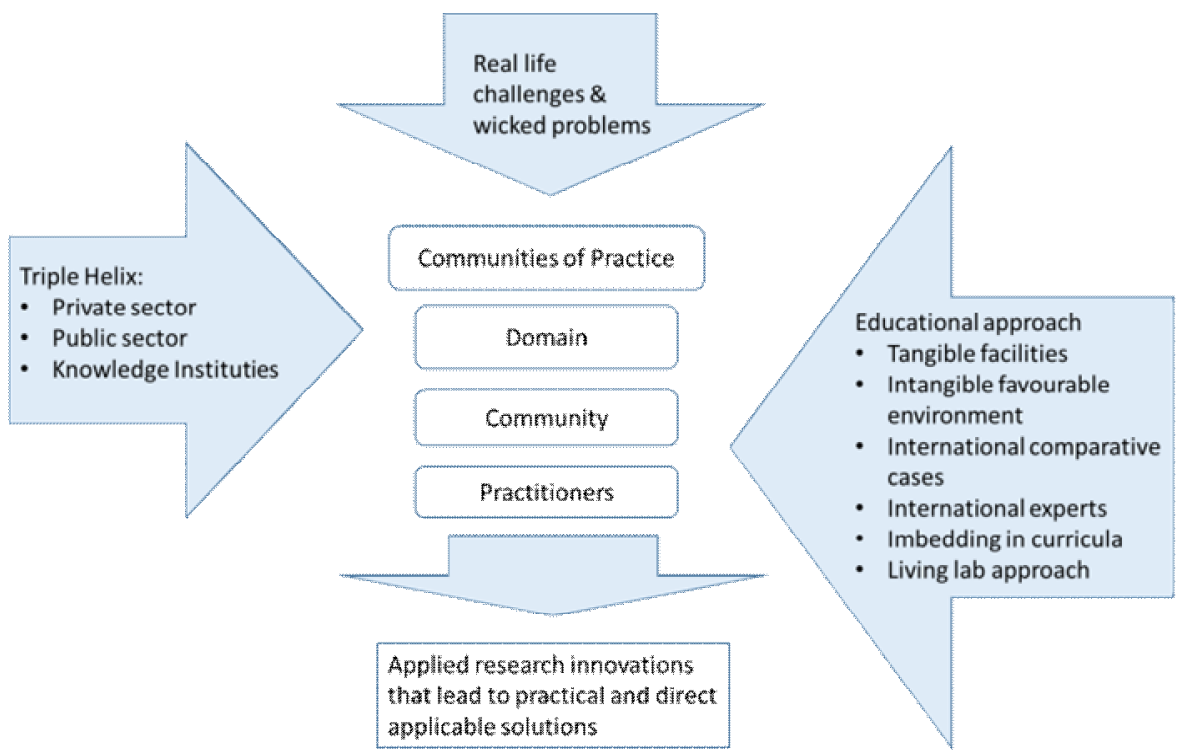

Fig. 4. RDM approach

\section{Results}

\subsection{Case study Manila "IWASTO"}

The 'IWASTO' initiative officially started with the signing of a Memorandum of Agreement (MOA) in November 2015 in the presense of: the mayors of Makati City, Pasig City, Taguig City and Pateros, the Rotary club of Makati Pasong Tamo, Department of Interior and Local government, The Netherlands Embassy, Rotterdam University of Applied Sciences, Groningen University of Applied Sciences, Tauw Group and small medium enterprises WaterWegen and INDYMO. The MOA embodies the commitment and support to rehabilitate and sustain the integrity of the decaying and heavily polluted rivers for the sake of ecological balance.

If we look closer at the IWASTO case, we see an immense problem, with multi stakeholders, which can be classified as a so called 'wicked problem,' the upper arrow in Fig. 4. The IWASTO case involves public stakeholders, namely the different mayors and barangay captains that signed the MOA. If we look at the left arrow in Fig. 4, we see that private partners are represented by the Dutch private partners Tauw Group., WaterWegen and Indymo. Looking at the knowledge institutes, we conclude that 2 international universities (Hanze University of Applied Sciences Groningen and Rotterdam University of Applied Sciences) are involved in the project. University of the Philippines participates in the project after establishing a Living Lab Water Philippines - Netherlands for which an MOU was signed during the second IWASTO conference in April 2016, and an MOU was signed with University of the Philippines to participate in the IWASTO Pasig river rehabilitation project.

At the RDM-campus a two-day event was organised by the Delta Talent Academy in the Netherlands, last September 2016 [20] The focus of the 2-day event was finding solutions for water quality improvement in Manila. 75 students participated representing 14 different universities in the Netherlands and 28 studies, worked together on the Manilla 
case and pitched multiple innovative, creative, technical and social solutions for water quality problems. In the RDM-strategy the multidisciplinary approach is an important asset.

A clear Community of Practice ( $\mathrm{CoP})$ is established: looking at the three components of the CoP, in the centre of Fig. 4, the domain of the IWASTO case is the river rehabilitation challenge. River rehabilitation is a clear domain with many different aspects such as wastewater treatment, illegal discharge of water, solid waste pollution, illegal residents along the river, and lack of enforcement of rules and regulations.

The community is present. Partners are defined in the IWASTO MOA. Different mayors and barangay captains committed themselves to IWASTO. As the project is evolving, different partners join the community.

The number of practitioners is increasing. As more students are involved in this project, more studies and research results are generated. The presences of Dutch and Philippine students in the community along the Pateros river generates more attention in both the Philippines and the Netherlands. University of the Philippines (UP) was involved in the IWASTO challenge, which took place last April 2016. More UP students and professors are involved in IWASTO, and more will be involved as the project evolves and upscaled to other regions in the Philippines as Davao and Cebu in 2017.

The Living Lab characteristics are also clearly present, since the location of the Pasig river is geographically bounded. The ongoing activities that are conducted make social and material alterations, and there is an explicit element of iterative learning and concrete results.

\subsection{Results IWASTO challenge 2016}

April 2016, the IWASTO challenge took place in Manila with 15 Dutch and Philippine students, and 5 Dutch and Philippine experts. Together they worked on locating and mapping specific pollution sources (Fig. 5).
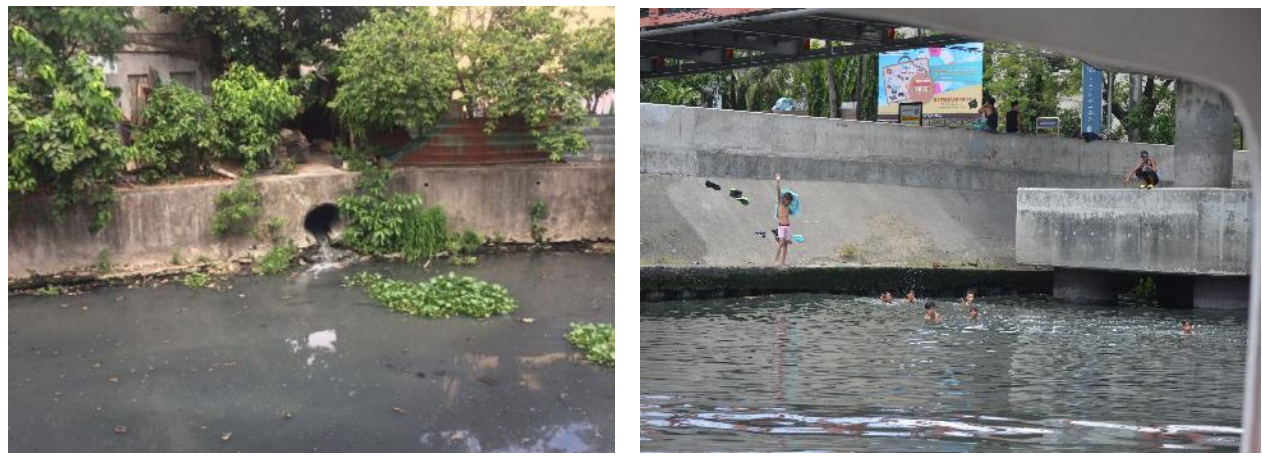

Fig. 5.a) Direct discharge of untreated wastewater in the Pateros river $\mathbf{5 b}$ ) the highly polluted rivers are being used as swimming water.

In order to locate the best locations for innovate solutions to address the water pollution new innovating tools were developed to monitor waterquality to analyse parameters as phosphate, nitrate, iron, electric conductivity, temperature and ph (Fig 6). 

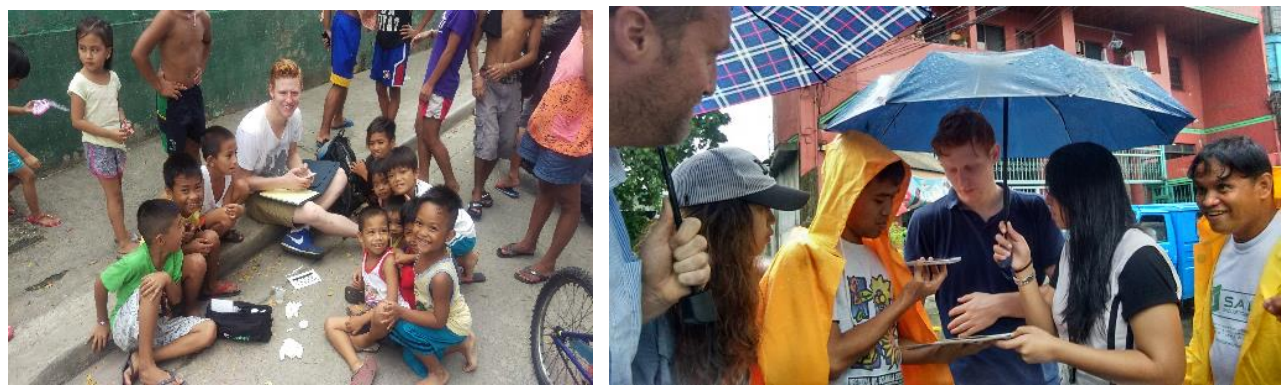

Fig. 6. a) new innovating tools to map waterquality in Manila with an app. 6b) Knowledge exchange on innovating waterquality measurments with PRRC (Pasig River Rehabilitation Committee).

Researchers have taken samples of the waterquality at several places in Manila which have been analysed using apps on smartphones and being mapped on open source maps (Fig. 7). In the near future, more test results and parameters will be analysed and uploaded real time with the smartphone application. In a fieldworkshop with the Pasig River Rehabilitation Committee, measurements with apps and grap samples are simulatiniously taken. The results from the test strips and labresults will be compared to judge the cost effectiveness of this new method for several organisations. All the results are geolocated on a map and more results can be uploaded, accessible by anyone with the smartphone application. At places that are highly polluted underwaterdrones with sensors will be applied to make detailed 3D scans of the water near polutions sources as sewer outlets and industrial areas [21].

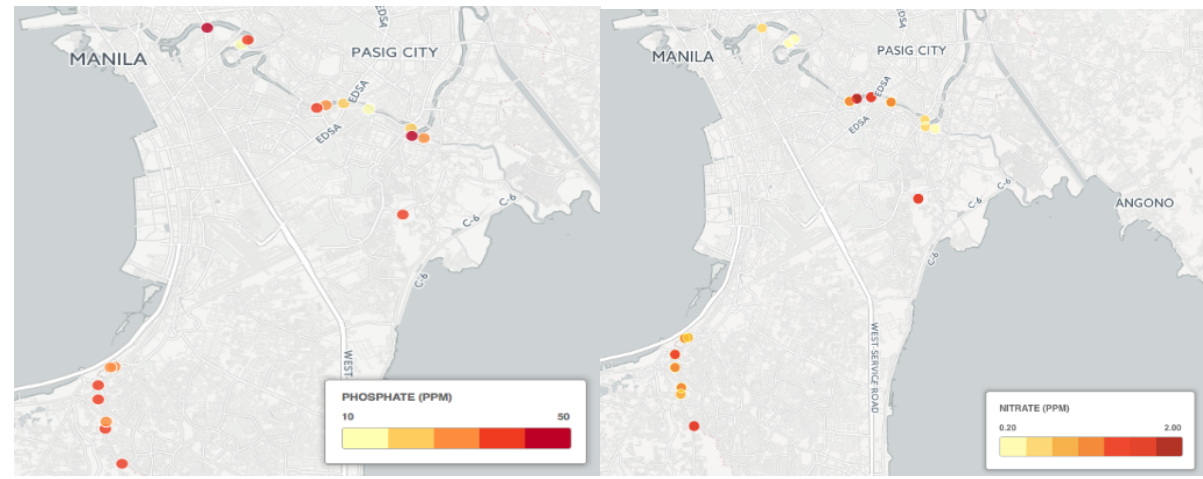

Fig. 7. Results of waterquality measurements in Manila (left: Phosphate, Right: Nitrate).

\section{Waste management tool 'Longganisa'}

An innovative design was developed by Dutch-Philippine students teams to catch solid waste from the rivers, the 'Longganisa' (sausage), shown in Fig 8. A floating 'sausage' accumulates the waste in the river by the flow of water. The waste is being gathered in the area of a segredation station where the floating waste (such as plastic) will be used to make products as chairs for schools and floating modulair platforms that can be used as bridges or boats. At highly polluted locations, the longganisa will also be constructed with filters to remove micropolutants from the water. 


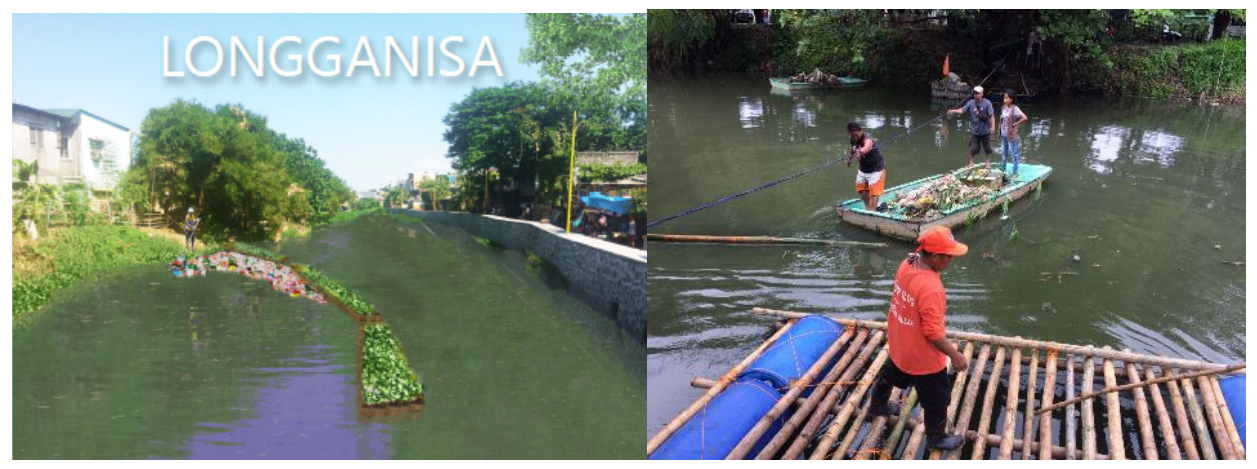

Fig. 8. Design of innovative 'Longganisa' to remove floating waste from rivers. 9b: the Longganisa constructed November 2016 (in the back is the old way of collecting trash from the river with a boat).

\section{Discussion}

The awareness increases with the number of practitioners. The IWASTO project has achieved the involvement of practitioners, but it is important to stay critical and continuously look for improvement and develop a joint vision. Looking at the right arrow in Fig. 4, we see that the criteria for a new educational approach are not yet fully met. The Tangible facilities, such as a campus or location were research can take place in an innovative environment, is not yet present in the area.

The intangible enabling environment, where practitioners and the community can meet and share ideas is also not present at the location. International comparative cases are present and Dutch practitioners and experts are present as well to share experiences from other cases. The case is also imbedded in the curricula of the Water Management course at Rotterdam and Groningen applied Universities, which enhances the number of practitioners. However, it is important that these kind of wicked problems are also embedded in the curricula of local universities. For the development of curricula that meet the current needs of the (global) society these kind of wicked problems should be included in the research agenda of universities.

The living lab is also present, although not yet completely. The Living Lab Approach at Rotterdam is characterised by mixed teams of both national students (from the country where the case is located) and international students. The Living Lab Approach needs more attention and will evolve in coming years so that the iterative learning aspect will be addressed.

\section{Conclusion}

The set-up of a Community of Practice (CoP) was effectively established and the 3 requirements were present:

1. The domain of the IWASTO case is the river rehabilitation challenge with its multidisciplinary challenges of wastewater treatment, discharge of water, solid waste pollution, illegal residents along the river, lack of enforcement of rules and regulations.

2. The community is present. Partners are defined in the IWASTO MOA. As the project is evolving, different partners join the community.

3. The awareness increased with the number of practitioners and actions. 
Important actions in this project and their concrete results are:

- 2016 IWASTO project: identification of stakeholders, signing MOA between stakeholders in Manila, raising awareness in both the Netherlands and the Philippines, improve commitment. An innovative design was developed by Dutch-Philippine students teams to catch solid waste from the rivers, the 'Longganisa', shown in Fig. 8.

- Delta Talent academy organised at RDM campus Rotterdam: 75 students participated, raising awareness and getting involved

- RDM Manila pressure cooker November 2016 with 15 Dutch students and a number of Philippine students.

- A project proposal was written which will help the Community of Practice to successfully develop, and to monitor progress in the cleaning of Pateros river.

- The successful implementation of the CoP resulted in interest in many countries such as India, Indonesia and China, and the upscaling and implementation is expected in the upcoming years.

- New monitoringmethods are developed (Fig. 6)

- Waterquality is measured and mapped (Fig. 7)

- Tailor made solutions are designed and implemented at highly polluted areas for micropolutants and waste management (Fig. 8).

\section{Recommendations}

International knowledge exchange with the lessons learned from countries such as the Netherlands will help other countries as the Philippines to avoid costly investments and to implement their strategies cost effectively in the limited space of urban dense areas in a short timeframe. Lessons learned that will be addressed are:

- The 'Meet in the middle' strategy as a combination of 'top down' and 'bottom up' engagement of all stakeholders and show quick concrete results that are needed to keep people involved at different decision levels.

- When solutions are designed, all stakeholders should be involved and attention should be given to the maintenance efforts of solutions to guarantee their efficiency over time. The triple Helix ensures that education, research and entrepreneurship are involved for the design, implementation and evaluation of solutions and so enhance the sustainable and innovative approach.

- When practitioners from other parts of the world visit a certain location where a challenge or problem is observed, they often get very much motivated and inspired to continue further research and studies on this specific topic. The challenge that they face becomes a motivator for pursuing further studies and an international career.

This study would not have been possible without the funding and collaboration within the projects WaterCoG, INXCES and the the long-term support we have received from the several stakeholders from The Netherlands and the Philippines.

\section{References}

[1] F. Boogaard, Climate adaptation from Groningen to Mae Phaem. Groningen: Kenniscentrum NoorderRuimte Hanzehogeschool Groningen, The Netherlands, (2016)

[2] Dale Israel, Entire Cebu province under state of calamity due to drought, CNN, (April 13, 2016)

[3] Janvic Mateo, Philippine temperature hits dangerous levels, The Philippine Star, (April 14, 2016) 
[4] T.D. Fletcher, H. Andrieu, and P. Hamel, Understanding, management and modelling of urban hydrology and its consequences for receiving waters; a state of the art. Advances in Water Resources., 51, 261-279, (2013)

[5] B.E. Hatt, T.D. Fletcher, C.J. Walsh and S.L. Taylor, The influence of urban density and drainage infrastructure on the concentrations and loads of pollutants in small streams. Environ. Manag., 34, 112-124, (2004)

[6] Pasig River Rehabilitation Commission. Annual Report 2014, Pasig river Rehabilitation commission (2014), Retrieved on September 25, 2016, from http://www.prrc.gov.ph/images/pdf/Transparent_Government/accomplishments/2014_ ar.pdf (2016)

[7] F.C. Boogaard, Z. Vojinovic and R. Heikoop, Storm Water and Wastewater Management for Improving Water Quality, Proc. - Global Water Safety Conf., Philippines, (April 25-29, 2016)

[8] Schets FM and v. W. The microbiological quality of the water in the Amsterdam canals. Bilhoven: RIVM Report (2007)

[9] Amsterdam City Swim. (2016), Retrieved on September 25, 2016 from Amsterdam city swim: https://www.amsterdamcityswim.nl/

[10]T. Venhoeven., Transit-Oriented Development \& Smart Micro City 公交导向的城市在中国与荷兰的发展, Beijing, (November, 2016)

[11]E. Wenger, Communities of Practice. International Encyclopedia of the Social@ @ Behavioral Sciences, 2339-2342, (2001)

[12] Y. H. Lee, and Y. Kim, Analyzing interaction in R\&D networks using the Triple Helix method: Evidence from Industrial R\&D programs in the Korean government. Technological Forecasting and Social Change, 93-105 (2016)

[13]L. Leydesdorff, The Triple Helix, Quadruple Helix, and an N-tuple of Helices, (2010), Retrieved on November 14, from http://www.leydesdorff.net/ntuple/ntuple.pdf

[14]N. Frantzeskaki, Wittmayer, J. and Loorbach, D., The role of partnerships in 'realising' urban sustainability in Rotterdam's City Ports Area, the Netherlands. Journal of Cleaner Production, 406-417 (2014)

[15]M. Guerrero, and D. Urbano, The impact of Triple Helix agents on entrepreneurial innovations'performance: An inside look at entreprises located in an emerging economy. Technological Forecasting \& Social Change,(2016)

[16]J. Tipping, F. Boogaard, R. Jaeger, A. Duffy, T. Klomp and M. Manenschijn, Climatescan.nl: The development of a web-based map application to encourage knowledge-sharing of climate-proofing and urban resilient projects, International water week 2015, Amsterdam (2015)

[17]RDM Centre of Expertise. RDM Centre of Expertise, (2016), Retrieved on September 25,2016 from http://www.rdmcoe.nl/

[18]J. Evans, R. Jones, A. Karvonen, L. Millard and J. Wendler, Living labs and coproduction: university campuses, Current Opinion in Environmental Sustainability, 16, $1-6,(2015)$

[19]J. Evans and A. Karvonen, Give Me a Laboratory and I Will Lower Your Carbon Footprint!' - Urban Laboratories and the Governance of Low-Carbon Futures. Int. J. of Urban and Regional Researc, 413-430 (2014)

[20]Delta Talent, Delta Talent Academy in volle gang, (2016), Retrieved on September 30, 2016, from Delta talent: http://www.deltatalent.nl/nieuws/delta-talent-academyvolle-gang 
[21]W. Schampers, 3D scan gives new dynamic insights in waterquality (in Dutch: 3Dscan geeft dynamisch inzicht in waterkwaliteit Groningse vijvers), vakblad riolering (November, 2016) 